\title{
Which form of nicotine replacement therapy is more effective for quitting smoking? A study in Tehran, Islamic Republic of Iran
}

G. Heydari, ${ }^{1}$ M. Marashian, ${ }^{2}$ A. Ebn Ahmady, ${ }^{3}$ M. Masjedi ${ }^{2}$ and H.A. Lando ${ }^{4}$

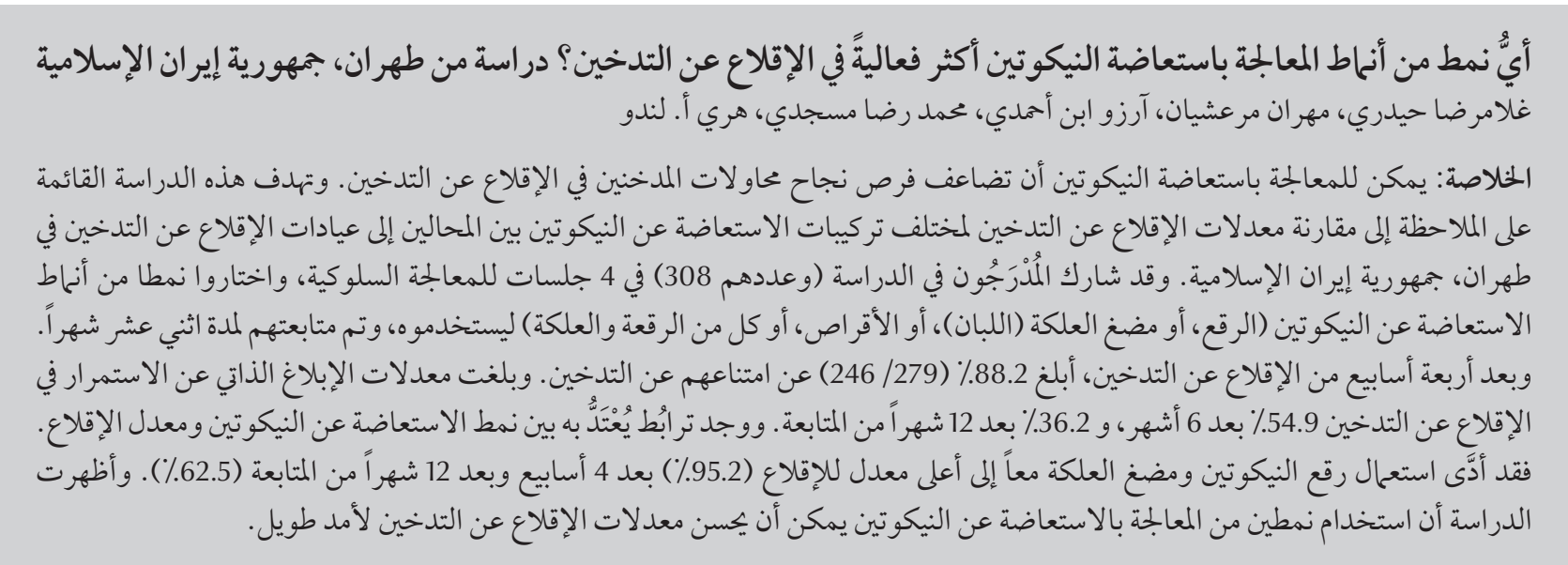

ABSTRACT Nicotine replacement therapy can double the chance of success for smokers attempting to quit. This observational study aimed to compare quit rates of different formulations of nicotine replacement among clients referred to a smoking cessation clinic in Tehran, Islamic Republic of Iran. Clients entering the study $(n=308)$ participated in 4 sessions of behavioural therapy, chose a type of nicotine replacement to use (patches, chewing gum, tablets or both patches and gum) and were followed up for 12 months. After 4 weeks of quitting, 88.2\% (246/279) reported abstaining from smoking. Self-reported maintenance rates for quitting were $54.9 \%$ after 6 months and $36.2 \%$ after 12 months follow-up. A significant correlation was found between type of nicotine replacement and quit rate. Use of nicotine patches and chewing gum together had the highest quit rate (95.2\%) after 4 weeks and at 12 months followup (62.5\%). Consuming 2 forms of nicotine replacement in therapy could result in enhanced rates of long-term quitting.

Quelle forme de thérapie de substitution à base de nicotine est plus efficace pour arrêter de fumer ? Une étude à Téhéran (République islamique d'Iran)

RÉSUMÉ La thérapie de substitution à base de nicotine peut doubler les chances de succès des fumeurs qui tentent d'arrêter. La présente étude d'observation visait à comparer les taux d'arrêt pour les différentes formulations des thérapies de substitution à base de nicotine chez des clients orientés vers un établissement de sevrage tabagique à Téhéran (République islamique d'Iran). Les clients sélectionnés dans l'étude $(n=308)$ ont participé à quatre sessions de thérapie comportementale, ont choisi un type de thérapie de substitution à base de nicotine (timbres, chewing-gums, comprimés ou timbres associés aux chewing-gums) et ont été suivis pendant 12 mois. Après 4 semaines de sevrage, 88,2\% (246/279) ont déclaré s'être abstenus de fumer. Les taux autodéclarés de maintien du sevrage étaient de $54,9 \%$ après 6 mois et de $36,2 \%$ après 12 mois de suivi. Une corrélation significative a été retrouvée entre le type de thérapie de substitution à base de nicotine et le taux de sevrage. L'utilisation des timbres de nicotine associés à des chewing-gums avait le taux de réussite le plus élevé $(95,2 \%)$ après 4 semaines et à 12 mois de suivi $(62,5 \%)$. Le recours à deux formes de thérapie de substitution à base de nicotine pourrait améliorer les taux de sevrage à long terme.

${ }^{1}$ Tobacco Prevention and Control Research Centre; ${ }^{2}$ National Research Institute of Tuberculosis and Lung Diseases; ${ }^{3}$ Department of Community Oral Health, School of Dentistry, Shahid Beheshti Medical University, Tehran, Islamic Republic of Iran (Correspondence to A. Ebn Ahmady: aebnahmady@dent.sbmu.ac.ir; aebnahmady@yahoo.com).

${ }^{4}$ Division of Epidemiology and Community Health, School of Public Health, University of Minnesota, Minneapolis, United States of America. Received: 11/07/11; accepted: 13/09/11 


\section{Introduction}

Tobacco use, particularly cigarette smoking, is now a global pandemic [1]. It is becoming increasingly common in Asia, while at the same time quitting rates remain low [2]. Many young smokers think they can quit easily, but find that they are already addicted and develop significant withdrawal symptoms when they attempt to stop smoking $[3,4]$. Tobacco dependency remains the major preventable cause of early mortality and morbidity in the developed world [5]. It is also a factor that may partly explain the high failure rate of smokers who attempt to maintain long-term abstinence $[6,7]$. In order to reduce this negative impact on worldwide health, comprehensive tobacco control approaches are needed, including offering effective therapy to aid smoking cessation for current smokers [8]. The Conference of the Parties for the Framework Convention on Tobacco Control recently adopted Article 14, calling on governments to provide cessation assistance to smokers [9] and offering help to quit smoking is one of the 6 components of the World Health Organization's (WHO) MPOWER package [9].

Two recommended quit methods in standard cessation programmes involve either gradual reduction of smoking prior to complete abstinence ("cutting down") or abrupt abstinence from cigarettes ("cold turkey"). Smokers have used these methods of smoking cessation in most cases without nicotine replacement therapy (NRT) or other pharmacological assistance [10]. Optimal treatment for tobacco dependency involves the combination of behavioural therapy and pharmacological treatment [11]. NRT is by far the most thoroughly researched therapy. Tests have shown that, if used correctly, it can double the chance of success, which is good news for those who have found withdrawal very hard on previous attempts $[8,11-13]$. The aim of NRT is to at least partially replace the nicotine from cigarettes. This reduces the withdrawal symptoms associated with smoking cessation, helping the smoker to resist the urge to smoke tobacco [14]. There are several forms of NRT available; these include patches, chewing gum, tablets, nasal sprays and inhalators [14]. The present study was conducted to compare quit outcomes for different formulations of NRT among clients attending a smoking cessation clinic in Tehran, Islamic Republic of Iran.

\section{Methods}

\section{Study setting and sample}

This was an observational study in which the efficacy of 4 formulations of NRT (patches, chewing gum, tablets or both patches and gum) were evaluated in helping smokers to quit. A review was made of the medical records of smokers were referred to the smoking cessation clinic of the Iranian National Research Institute of Tuberculosis and Lung Diseases (NRITLD). This clinic was established in 1998 by the NRITLD at Shahid Beheshti Medical University in association with the municipality of district number 14. Monthly cessation courses are held for women and men separately. These courses comprise 7 sessions each lasting for 2 hours. In these courses the physicians use educational methods, consultations, cognitive-behavioural therapy and pharmacotherapy to help smokers quit smoking. Usually 15-20 smokers participate in each course. All smokers (volunteers) who were referred to the smoking cessation clinic from October 2009 to October 2010 and were followed for 12 months were entered into this study. Of the 310 smokers who were enrolled, initial data were missing for 2 , and therefore 308 clients entered the study.

\section{Data collection}

\section{Registration and baseline data}

At the 1st session, clients were registered and background data were collected using a questionnaire. This included personal and demographic data (age, sex, marital status, level of education and occupation), smoking habits (reasons for smoking, the number of cigarette packs smoked per day during the smoking years) and the Fagerström test which is a standard instrument to evaluate cigarette (nicotine) dependency using items including time, situations and places of smoking as well as number of cigarettes smoked per day [15]. It contains 6 items concerning: how long after waking up the first cigarette is smoked, the most desired cigarette of the day, period of time in the day when most cigarettes are smoked, tendency to smoke during illness and difficulties of smoking in banned or non-smoking areas. We scored the Fagerström questionnaire as $0-4=$ mild, $5-7=$ moderate and $8-10=$ severe dependence. Any person scoring $\geq 7$ was chosen as a candidate for NRT. We also asked about the reasons for smoking, the number of cigarette packs smoked per day during the smoking years (pack/year), the number of absences from sessions and the outcome of the course. After they had completed the questionnaire, smokers were physically examined for vital signs, respiratory and cardiac auscultation and expiratory carbon monoxide concentration.

\section{Intervention}

At the 2nd session, which took place 1 week after registration, clients were clinically evaluated and asked about any medical or psychological problems they suffered. At this session, the treatment plan was adjusted as needed and behavioural therapy and the strategy for changing smoking habits was discussed. In this study, we combined the "cold turkey" method of cessation with pharmacological treatment (NRT) 
plus cognitive behavioural therapy to increase the likelihood of cigarette cessation. Instructions were given to improve the clients' readiness to quit smoking through education about changing the routine smoking habits for each person. The clients were requested to set a firm quit date for the next session.

The $3 \mathrm{rd}$ session was scheduled 1 week later. This was the quit date and the day of starting NRT and completing behavioural therapy. Participants could select their preferred NRT method considering the cost of each and following counselling guidance. The types of NRT and the instructions for correct use as well as the price of each method were discussed and clients received advice about which form of NRT might be most suitable. However, the final choice of NRT was left to the client. The recommended duration of use of NRT was at least 6 weeks. The NRT options used in this study included patches, chewing gum and tablets. Clients also had the option of combining patches and gum. Patch usage had 3 steps: 52.5, 35, $17.5 \mathrm{mg} /$ $\mathrm{cm}^{2}$ patches were used for 2 weeks each with daily replacement. Nicotine gum was of 2 types: $2 \mathrm{mg}$ and $4 \mathrm{mg}$ were prescribed to be used as needed with a maximum of 12 pieces per day as needed. Nicotine tablets also were prescribed as needed with a daily maximum of 8 tablets.

\section{Follow up}

At the 4th session, 4 weeks after the quit date, clients were contacted at the clinic to ask them if they had given up smoking, and also to evaluate withdrawal symptoms, quit-related problems, relapses and potentially dangerous situations threatening continued abstinence. Follow-up assessments were then performed by telephone 6 months and 12 months after the quit date.

\section{Research ethics}

All clients selected their preferred quit methods and were informed that they could exit the study whenever they wished. Registration forms and charts were safeguarded by researchers in order to maintain confidentiality.

\section{Outcome measures}

We defined successful quitting as the absence of any smoking, even a single cigarette, at 1-year follow-up. Intermediate abstinence outcomes were assessed at each session following the quit date and at 6 and 12 months.

\section{Analysis of data}

Demographic data as well as the results of questionnaires and follow up contacts were entered and analysed using SPSS, version 16. Chi-squared tests were performed and when required the Fisher exact test was used to evaluate the correlation between 2 variables. In addition, logistic regression was performed to find the odds ratio for efficacy of each NRT method when the chi-squared of the cross-tables was significant $(P<$ $0.05)$.

\section{Results}

\section{Background data}

A total of 308 individuals were recruited to in the study and used at least 1 form of NRT. These included 211 males (68.5\%) and 97 females (31.5\%). The mean age was 42.4 (standard deviation 13.4) years (median age 41, range 19-80 years). Fagerström scores were distributed as follows: 89 (28.9\%) mild, 111 (36.0\%) moderate, and 108 (35.1\%) severe. Although the difference was not statistically significant, more male clients reported severe dependency than did females (38\% versus $25 \%$ ), whereas more female participants reported moderate dependence (44\% versus $31 \%)(P=0.128)$.

Table 1 shows the choice of type of NRT by sex, age, level of dependency and outcome at follow-up. Of those entering the study, 31 (1.10\%) selected nicotine patches, while 161 (52.3\%) chose nicotine gum, 29 (9.4\%) chose nicotine tablets and 87 (28.3\%) preferred 2 types of NRT simultaneously. There was no significant relationship between the NRT forms selected by the clients as a function of nicotine dependence scores $(P=0.88)$.

\begin{tabular}{|c|c|c|c|c|c|c|c|c|c|}
\hline \multirow{2}{*}{$\begin{array}{l}\text { Type of nicotine } \\
\text { replacement therapy }\end{array}$} & \multirow{2}{*}{$\begin{array}{c}\text { Total entering } \\
\text { study } \\
\text { No. }\end{array}$} & \multicolumn{2}{|c|}{ Male } & \multicolumn{2}{|c|}{ Female } & \multicolumn{2}{|c|}{ Age years } & \multicolumn{2}{|c|}{ Fagerström score } \\
\hline & & No. & $\%$ & No. & $\%$ & Mean & SD & Mean & SD \\
\hline All methods & 308 & 211 & 68.5 & 97 & 31.5 & 42.4 & 13.4 & 5.8 & 2.1 \\
\hline Gum & 161 & 114 & 70.8 & 47 & 29.2 & 42.1 & 14.6 & 5.6 & 2.5 \\
\hline Patches & 31 & 20 & 64.5 & 11 & 35.5 & 41.9 & 8.9 & 5.8 & 3.1 \\
\hline Tablets & 29 & 21 & 72.4 & 8 & 27.6 & 43.2 & 10.1 & 5.7 & 2.6 \\
\hline Patches + gum & 87 & 56 & 64.4 & 31 & 35.6 & 46.1 & 12.8 & 6.0 & 2.8 \\
\hline$P$-value & & \multicolumn{4}{|c|}{0.66} & \multicolumn{2}{|c|}{$0.30^{\mathrm{a}}$} & \multicolumn{2}{|c|}{$0.88^{a}$} \\
\hline
\end{tabular}




\section{Abstinence rates}

After 4 weeks of quitting 29 clients had left the study and the quit rate of those remaining in the study was $246 / 279$ (88.2\%). After 6 and 12 months a further 66 clients had relapsed. At 6 months follow-up 135/246 (54.9\%) clients who had quit after 4 weeks reported maintaining abstinence and at 12 months 89/246 (36.2\%) reported that they were still abstaining.

The outcomes after 4 weeks and the other 2 follow-up contacts are summarized by sex and age group in Table 3. A statistically significant correlation was detected between sex and quit rate only at the first evaluation at 4 weeks $(P=0.048)$. Women tended to be less successful than men at 6 months follow-up in the younger age groups while slightly more successful than men after 12 months at the older age groups but these differences were not significant.

\section{Abstinence rate by type of therapy}

Using the chi-squared test a significant correlation was found between the formulation of NRT and quit rate at all evaluation stages. After 4 weeks clients using both patches and gum had the highest quit rate of all the methods; $95.2 \%$ of those who started on this therapy reported quitting (Table 2) $(P=0.028)$. At 6 months follow-up those using nicotine patches had the highest abstinence rate $(91.7 \%)(P<$
0.001). At the end of the programme (at 12 months follow-up), however, use of patches and gum together had the best outcome with $62.5 \%$ maintaining quitting versus only $16.7 \%$ for those using patches $(P<0.001)$ (Table 2).

\section{Discussion}

Implementing smoking cessation methods is an essential issue in tobacco control programmes. The recent adoption of article 14 of the WHO Framework Convention on Tobacco Control called for dissemination of effective treatment by all parties to this treaty (of which Islamic Republic of Iran is one) [14]. Unfortunately, however, only a few countries have effectively implemented and disseminated smoking cessation services. Often these services are not available or are unaffordable for most tobacco users [8]. Most of those who have quit have done so without formal assistance. However, success rates for interventions that include either counselling or medication are substantially higher than for unaided quit attempts.

It may be especially important to offer cessation services to highly dependent smokers who have not been able to quit on their own, as well as to individuals at especially high risk or with already existing smoking-related disease. Smoking cessation services can be widely provided at low prices, especially when counselling is conducted by trained lay providers [1]. Currently, however, medications are often priced far too high for tobacco users in low- and middle-income countries and substantially less costly medication options may be needed. Commitment to quitting may be greater if individuals are required to pay part of the cost of treatment [11]. Smoking cessation treatment has been demonstrated to be highly effective when compared with other commonly accepted medical interventions and prevention services $[8,11-13]$. The efficacy of counselling and medications including nicotine replacement therapy in smoking cessation is well-established $[13,16]$.

The aim of the current study was to evaluate a specialized smoking cessation service which included several options for NRT. The results of our study showed that nicotine chewing gum was the preferred method among smokers given a choice of gum, patches, tablets or a combination. A total of $52.3 \%$ used gum alone and most of those who chose combination medications used the gum as well. Low price and easy access undoubtedly influenced this preference for gum. Nicotine patches have been suggested to be more suitable for those that smoke steadily throughout the day, while gum allows flexibility for those who smoke primarily in response to cravings or stress [13].

\begin{tabular}{|c|c|c|c|c|c|c|c|}
\hline \multirow[t]{3}{*}{ Type of NRT } & \multirow{3}{*}{$\begin{array}{c}\text { Total remaining in } \\
\text { study } \\
\text { No. }\end{array}$} & \multirow{2}{*}{\multicolumn{2}{|c|}{$\begin{array}{l}\text { Quit smoking after } 4 \\
\text { weeks }\end{array}$}} & \multicolumn{4}{|c|}{ Maintained quitting: } \\
\hline & & & & \multicolumn{2}{|c|}{ After 6 months } & \multicolumn{2}{|c|}{ After 12 months } \\
\hline & & No. & $\%^{\mathrm{a}}$ & No. & $\%^{\mathrm{b}}$ & No. & $\%^{\mathbf{b}}$ \\
\hline All methods & 279 & 246 & 88.2 & 135 & 54.9 & 89 & 36.2 \\
\hline Gum & 143 & 120 & 84.0 & 55 & 45.8 & 31 & 25.8 \\
\hline Patches & 27 & 24 & 88.8 & 22 & 91.7 & 4 & 16.7 \\
\hline Tablets & 25 & 22 & 88.0 & 4 & 18.2 & 4 & 18.2 \\
\hline Patches + gum & 84 & 80 & 95.2 & 54 & 67.5 & 50 & 62.5 \\
\hline$P$-value & & \multicolumn{2}{|c|}{0.028} & \multicolumn{2}{|c|}{$<0.001$} & \multicolumn{2}{|c|}{$<0.001$} \\
\hline
\end{tabular}

aPercentage of those entering this phase of the study; ${ }^{b}$ Percentage of those who had quit after 4 weeks. 


\begin{tabular}{|c|c|c|c|c|c|c|c|}
\hline \multirow[t]{3}{*}{ Age/sex } & \multirow{3}{*}{$\begin{array}{c}\text { Total remaining } \\
\text { in study } \\
\text { No. }\end{array}$} & \multirow{2}{*}{\multicolumn{2}{|c|}{$\begin{array}{l}\text { Quit smoking after } 4 \\
\text { weeks }\end{array}$}} & \multicolumn{4}{|c|}{ Maintained quitting: } \\
\hline & & & & \multicolumn{2}{|c|}{ After 6 months } & \multicolumn{2}{|c|}{ After 12 months } \\
\hline & & No. & $\%^{\mathrm{a}}$ & No. & $\%^{b}$ & No. & $\%^{b}$ \\
\hline \multicolumn{8}{|l|}{ 19-31 years } \\
\hline Male & 47 & 42 & 89.4 & 21 & 50.0 & 8 & 19.0 \\
\hline Female & 19 & 17 & 89.5 & 2 & 11.8 & 0 & 0.0 \\
\hline \multicolumn{8}{|c|}{$32-40$ years } \\
\hline Male & 49 & 45 & 91.8 & 29 & 64.4 & 15 & 33.3 \\
\hline Female & 11 & 9 & 81.8 & 1 & 11.1 & 1 & 11.1 \\
\hline \multicolumn{8}{|l|}{$41-52$ years } \\
\hline Male & 41 & 39 & 95.1 & 21 & 53.8 & 14 & 35.9 \\
\hline Female & 41 & 30 & 73.2 & 23 & 76.7 & 15 & 50.0 \\
\hline \multicolumn{8}{|l|}{$>52$ years } \\
\hline Male & 51 & 45 & 88.2 & 23 & 51.1 & 21 & 46.7 \\
\hline Female & 20 & 19 & 95 & 15 & 78.9 & 15 & 78.9 \\
\hline \multicolumn{8}{|l|}{ All ages } \\
\hline Male & 188 & 171 & 91 & 94 & 55.0 & 58 & 33.9 \\
\hline Female & 91 & 75 & 82.4 & 41 & 54.7 & 31 & 41.3 \\
\hline
\end{tabular}

aPercentage of those entering this phase of the study; ${ }^{b}$ Percentage of those who had quit after 4 weeks.

At the end of treatment the selfreported abstinence rate was $88.2 \%$ and after 6 and 12 months follow-ups maintenance of quitting was $54.9 \%$ and $36.2 \%$ respectively. These figures compare quite favourably to the results of other studies [8,11-13]. The results also indicated that the quit rate among women (at the end of treatment after the 4th session) was significantly lower than for men, especially for those who were younger, while the abstinence rate for women at 12 months follow-up was slightly higher than that for men, especially for those who were older. Differences in abstinence rates as a function of age were not statistically significant, however.

The results suggested better longterm abstinence at 12 months follow-up for those who used 2 forms of nicotine replacement. However, although quit rates were better for combination NRT at 4 weeks, at 6 months follow-up there was a significant trend for higher abstinence rates among those who selected nicotine patches. The results of this study suggest that using 2 forms of NRT could lead to higher success rates based on 1-month and 12-month outcomes (however, this advantage for 2 forms of NRT was not evident at 6 months). The abstinence rates for combined NRT were quite encouraging, with a self-reported quit rate of $95.2 \%$ after 4 weeks and a still very impressive $62.5 \%$ after 12 months. It appears plausible that use of combined NRT was effective in reducing withdrawal symptoms and that this reduction contributed to longterm abstinence.

The current study had some major limitations, including the fact that participants self-selected NRT or a combination. In addition, abstinence outcomes were based on self-reporting. However, we assumed that the pressure to falsely report abstinence was not likely to differ as a function of NRT type.

Although no significant correlation between participants' sex and success rate was detected, women were slightly less successful than men at 6 months follow-up while slightly more successful than men after 12 months. Women may be less nicotine-dependent than men and there tends to be less acceptance of smoking for women than men in Iranian society. Tobacco use is far more prevalent among men than among women in the Islamic Republic of Iran [9]. Men may also come into greater contact with other men who smoke, thus making quitting more challenging. Future work is needed to assess the relative effectiveness of different forms and combinations of NRT in a randomized study design. Our data in this study confirm what is already known regarding the use and acceptability of treatment including NRT for those referred to tobacco quitting programmes. These results are quite encouraging, as are the 12-month abstinence rates for those who selected 2 forms of therapy.

\section{Acknowledgements}

The researcher team wishes to acknowledge all colleagues of the Tobacco Prevention and Control Research Center and National Research Institute of Tuberculosis and Lung Diseases who have helped to conduct this study. 


\section{References}

1. Tobacco addiction. Fact sheet 2007. National Institutes of Health (http://www.nih.gov/about/researchresultsforthepublic/ Tobaccoaddiction.pdf, accessed 2 September 2011).

2. Huxley R et al. Asia Pacific Cohort Studies Collaboration. Impact of smoking and smoking cessation on lung cancer mortality in the Asia-Pacific region. American Journal of Epidemiology, 2007, 165:1280-1286

3. Charlton A et al. Youth and cigarette smoking (www.heartforum. co.uk, accessed 2 September 2011).

4. McNeill AD et al. Cigarette withdrawal symptoms in adolescent smokers. Psychopharmacology, 1986, 90:533-536.

5. Lung cancer and other lung problems from smoking. WebMD [online factsheet] (http://www.webmd.com/hw-popup/ lung-cancer-and-other-lung-problems-from-smoking, accessed 2 August 2012).

6. John $U$ et al. Nicotine dependence, quit attempts, and quitting among smokers in a regional population sample from a country with a high prevalence of tobacco smoking. Preventive Medicine, 2004, 38:350-358.

7. Balfour DJ. The pharmacology underlying pharmacotherapy for tobacco dependence: a focus on bupropion. International Journal of Clinical Practice, 2001, 55:53-57.

8. Hays JT, Ebbert JO. Bupropion for the treatment of tobacco dependence: guidelines for balancing risks and benefits. CNS Drugs, 2003, 17:71-83.
9. WHO report on the global tobacco epidemic, 2011: warning about the dangers of tobacco. Geneva, World Health Organization, 2011.

10. Wakai $\mathrm{K}$ et al. Decrease in risk of lung cancer death in Japanese men after smoking cessation by age at quitting: pooled analysis of three large-scale cohort studies. Cancer Science, 2007, 98:584-589.

11. Cheong Y, Yong HH, Borland R. Does how you quit affect success? A comparison between abrupt and gradual methods using data from the International Tobacco Control Policy Evaluation Study. Nicotine and Tobacco Research, 2007, 9:801-810.

12. Bolin $\mathrm{K}$, Lindgren B, Willers $\mathrm{S}$. The cost utility of bupropion in smoking cessation health programs: simulation model results for Sweden. Chest, 2006, 129:651-660.

13. The most common smoking cessation methods. QuitSmokingSupport.com [online factsheet] (http://www.quitsmokingsupport.com/, accessed 2 August 2012).

14. WHO Framework Convention on Tobacco Control. Geneva, World Health Organization, 2003.

15. Heatherton TF et al. The Fagerström test for nicotine dependence: a revision of the Fagerström tolerance questionnaire. British Journal of Addiction, 1991, 86:1119-1127.

16. Silagy $\mathrm{C}$ et al. Nicotine replacement therapy for smoking cessation. Cochrane Database of Systematic Reviews, 2004, (3):CD000146.

\section{Treatment of tobacco dependence}

Treatment of tobacco dependence should be an integral part of any comprehensive tobacco control programme as indicated in the WHO FCTC. Article 14 of the WHO FCTC addresses the issue of tobacco dependence treatment. It obligates Parties to this Convention to endeavour to: a) design and implement effective programmes aimed at promoting the cessation of tobacco use, in such locations as educational institutions, health care facilities, workplaces and sporting environments; b) include diagnosis and treatment of tobacco dependence and counselling services on cessation of tobacco use in national health and education programmes, plans and strategies, with the participation of health workers, community workers and social workers as appropriate; $\mathrm{c}$ ) establish in health care facilities and rehabilitation centres programmes for diagnosing, counselling, preventing and treating tobacco dependence; and d) collaborate with other Parties to facilitate accessibility and affordability for treatment of tobacco dependence including pharmaceutical products pursuant to Article 22 [3].

Source: Integration of tobacco cessation efforts into primary health care in the Eastern Mediterranean Region (WHO$\mathrm{EM} / \mathrm{TFI} / 077 / \mathrm{E})$. 